\title{
Association of genetic polymorphisms in DNMT3A with the progression of gastric mucosal atrophy and susceptibility to gastric cancer in Japan
}

\author{
WU JING ${ }^{1}$, TOSHIMI OTSUKA ${ }^{1}$, MASAKATSU NAKAMURA ${ }^{1}$, NAOKO SAKURAI ${ }^{1}$, HIKARU TAKANO ${ }^{1}$, \\ TASUKU HAYASHI ${ }^{1}$, MASAFUMI OTA ${ }^{1}$, TOMOE NOMURA ${ }^{1}$, RANJI HAYASHI ${ }^{1}$, TAKEO SHIMASAKI ${ }^{1}$, \\ TOMOMITSU TAHARA ${ }^{2}$, TOMOYUKI SHIBATA ${ }^{2}$ and TOMIYASU ARISAWA ${ }^{1}$
}

\footnotetext{
${ }^{1}$ Department of Gastroenterology, Kanazawa Medical University, Uchinada-machi, Ishikawa 920-0293;

${ }^{2}$ Department of Gastroenterology, Fujita Health University, Kutsukake-cho, Toyoake 470-1192, Japan
}

Received August 30, 2018; Accepted January 2, 2019

DOI: $10.3892 / \mathrm{ol} .2019 .9948$

\begin{abstract}
The aim of the present study was to investigate whether single nucleotide polymorphisms in the DNMT3A gene are associated with susceptibility to gastric cancer in the Japanese population. The present case-control study examined the associations between single nucleotide polymorphisms (rs6733868 and rs13428812) in DNMT3A and cancer susceptibility in 343 patients with gastric cancer and 708 subjects without gastric malignancies on upper gastro-duodenal endoscopy. Of 708 controls, 409 were classified into two groups histologically: 99 cases with and 310 cases without gastric mucosal atrophy. Overall, homozygosity for the DNMT3A rs6733868 minor allele was significantly associated with a reduced risk of gastric cancer (odds ratio [OR], 0.621; 95\% confidence interval $[\mathrm{CI}], 0.402-0.958 ; \mathrm{P}=0.031$ ), especially of the intestinal type (OR, 0.494; 95\% CI, 0.274-0.890; $\mathrm{P}=0.019)$. In subjects $>60$ years, rs6733868 minor allele homozygosity was significantly associated with gastric cancer susceptibility. Carriers of the rs6733868 minor allele had a reduced risk of severe gastric mucosal atrophy (OR, 0.495; 95\% CI, 0.299-0.826; $\mathrm{P}=0.0069)$. In addition, the number of minor alleles of both rs6733868 and rs13428812 was significantly correlated with the risk of Helicobacter pylori (HP) infection $(\mathrm{P}=0.0070$ and $\mathrm{P}=0.0050$, respectively). However, rs13428812 was not associated with severe gastric mucosal atrophy or gastric carcinogenesis. The present results suggest that DNMT3A polymorphisms serve roles in the progression from HP infection to gastric mucosal atrophy and gastric carcinogenesis in terms of degree and manner.
\end{abstract}

Correspondence to: Professor Tomiyasu Arisawa, Department of Gastroenterology, Kanazawa Medical University, 1-1 Daigaku, Uchinada-machi, Ishikawa 920-0293, Japan

E-mail: tarisawa@kanazawa-med.ac.jp

Key words: DNMT3A, genetic polymorphism, gastric cancer, atrophic gastritis, Helicobacter pylori infection

\section{Introduction}

The incidence of gastric cancer (GC) varies worldwide; the disease is four times more common in Japan than in the UK and occurs in younger patients (1). In Japan, 50,000 people die of GC annually. GC progression involves a variety of gene alterations and a number of specific events (2), such as overexpression of oncogenes and inactivation of tumor suppressor genes. Helicobacter pylori (HP) infection and consequent atrophic gastritis are regarded as risk factors for GC. Research has shown that HP infection can cause GC via atrophic gastritis $(3,4)$. Severe gastric atrophy $(\mathrm{SA})$ and corpus-predominant gastritis, intestinal metaplasia (IM), and dysplasia are well-known predisposing factors for GC $(5,6)$. Previous research suggested that gastric carcinogenesis involves three steps: HP infection, development of gastric precancerous conditions, and carcinogenesis (7). However, relatively few cases of HP infection progress to GC. This discrepancy has prompted considerable research examining potential associations between genetic polymorphisms and the risk of progression from precancerous conditions to GC.

Methylation of several genes has been reported in many cancers, including GC (8). The DNA methyltransferase (DNMT) family includes three active mammalian homologs: DNMT1, 3a, and 3b. DNMT3a and DNMT3b are considered de novo enzymes that play critical roles in the dynamic DNA methylation process during embryogenesis and pathogenesis (9). In both GC and para-cancerous tissues, the expression of DNMTs is significantly higher than in normal tissues (10), which suggests that DNMT overexpression is involved in the development of gastric mucosal atrophy and subsequent tumorigenesis. Many studies have reported an association between rs1550117, a notable polymorphism in the DNMT3A gene, and susceptibility to various cancers, including GC $(11,12)$. However, no significant association between rs1550117 and GC susceptibility has been reported $(13,14)$. Thus, the influence of DNMT3A polymorphisms upon GC susceptibility remains unclear, especially in the Japanese population.

In this study, we investigated potential associations between SA and GC susceptibility and two DNMT3A polymorphisms: 
rs6733868 C>G (in linkage with rs7605753, rs13427202, rs7590760, rs6749992, and rs7586294) and rs13428812 A>G (in linkage with rs7583409 and rs7578575).

\section{Materials and methods}

Clinical samples. All subjects were enrolled at the Endoscopy Center of Fujita Health University Hospital or Kanazawa Medical University Hospital between April 2005 and March 2014. The study involved 343 patients with GC (GC group) and 708 subjects with no evidence of gastric malignancies (non-GC group) on upper gastro-duodenal endoscopy. In addition, 409 of 708 controls in which the degree of histologic gastritis could be assessed according to the updated Sydney system using biopsy specimens obtained from antrum (15) were classified into two groups: 99 patients in the SA group (atrophy score of 3 or metaplasia score $\geq 2$ ) and 310 patients in the non-SA group. Diagnosis of all GCs was made histologically at the Division of Pathology of each hospital. Patients with severe systemic diseases, malignancies in other organs, or who had received nonsteroidal anti-inflammatory drugs, antibiotics, or HP eradication treatment were excluded. We judged HP infection status as positive when the rapid urease test, urea breath test, or histologic test was positive.

The Ethics Committees of Fujita Health University and Kanazawa Medical University approved the protocol, and written informed consent was obtained from all participating subjects.

Single nucleotide polymorphism selection and detection. We selected the Tag polymorphism with high minor allele frequency (MAF) in the DNMT3A gene region. We selected rs6733868 $\mathrm{C}>\mathrm{G}$ in a large linkage disequilibrium block with a Hardy-Weinberg equilibrium (HWE) P-value $>0.05$ and MAF $>0.30$ determined according to the LD TAG SNP selection database (https://snpinfo.niehs.nih.gov/snpinfo/snptag.html, Fig. 1). In addition, another SNP with a high MAF (rs13428812 $A>G$ ) that had been investigated in a previous study based on its association with GC susceptibility (13) also was selected. This polymorphism is in linkage with rs7578575 (Fig. 1).

Sample stocks of DNA isolated from peripheral blood were used in the study. Genotyping of DNMT3A polymorphisms was carried out using polymerase chain reaction(PCR)-single-strand conformation polymorphism (SSCP) methods, as reported previously $(16,17)$. The rs6733868 and rs13428812 genotypes were determined using the following primer pairs: for rs6733868, forward 5'-ctagctagcgggagtcgctgtc-3' and reverse 5'-ctcctggctgtgaagcggaag-3'; for rs13428812, forward 5'-ccccat catgtcagataccetctg-3' and reverse 5'-ccttcctaggggacaccettctat $\mathrm{t}-3$ '. PCR was carried out in a $20-\mu 1$ reaction volume containing $0.1 \mu \mathrm{g}$ of genomic DNA. The DNA was denatured at $95^{\circ} \mathrm{C}$ for $3 \mathrm{~min}$, followed by 35 cycles at $96^{\circ} \mathrm{C}$ for $15 \mathrm{sec}, 61^{\circ} \mathrm{C}$ for $30 \mathrm{sec}$, and $72^{\circ} \mathrm{C}$ for $30 \mathrm{sec}$, with final extension at $72^{\circ} \mathrm{C}$ for $5 \mathrm{~min}$. PCR conditions for amplification of rs6733868 and rs13428812 were the same. Thereafter, $2 \mu \mathrm{l}$ of the PCR product was denatured with $10 \mu \mathrm{l}$ of formamide (Sigma-Aldrich Co., St. Louis, MO, USA) at $90^{\circ} \mathrm{C}$ for $5 \mathrm{~min}$. SSCP was carried out at $18^{\circ} \mathrm{C}$. We used a Gene Phor DNA separation system with Gene Gel Excel 12.5/24 (GE Health Care Bio-Sciences AB, Stockholm, Sweden), after which the denatured single-strand DNA bands were detected using a DNA silver staining kit (GE Health Care Bio-Sciences AB).
Statistical analysis. The HWE of each allele was assessed using a $\chi^{2}$ test. Data are expressed as mean \pm SD. Differences in mean age of patients in each group were evaluated using the Student's t-test. Differences in ratios of HP infection status and male to female patients were evaluated using Fisher's exact test. Allele and genotype frequencies were determined by direct counting. Differences in allele count also were evaluated using Fisher's exact test. The strength of association between allele frequencies and disease was assessed by calculating the odds ratio (OR) and $95 \%$ confidence interval (CI) by logistic regression analysis. Adjusted ORs considered age, gender, and HP infection status. An adjusted analysis also was performed by logistic regression analysis after adjustment for gender, age, and HP infection status. For all analyses, the level of significance was set at $\mathrm{P}<0.05$. Analyses were performed using Stata software (version 13; StataCorp LP, College Station, TX, USA).

\section{Results}

Characteristics of subjects and the frequencies of genotypes. Single-strand DNAs of rs6733868 and rs13428812 were clearly separated by SSCP (Fig. 2). The characteristics of subjects in this study are summarized in Table I. The mean age, male to female ratio, and HP positivity ratio were significantly higher in the GC group than in the non-GC group. The distribution of the rs6733868 $\mathrm{C}>\mathrm{G}$ genotype in the GC group was $130 \mathrm{CC}, 181 \mathrm{CG}$, and $32 \mathrm{GG}$. The distribution of the rs6733868 $\mathrm{C}>\mathrm{G}$ genotype in the non-GC group was $253 \mathrm{CC}, 338 \mathrm{CG}$, and $117 \mathrm{GG}$ (HWE $\mathrm{P}=0.82)$. The rs6733868G allele frequency in the GC and non-GC groups was 35.7 and $40.4 \%$, respectively $(\mathrm{P}=0.04)$. In addition, the frequency of the rs6733868 GG homozygote differed significantly between the $\mathrm{GC}$ and non-GC groups $(\mathrm{P}=0.0018)$. The distribution of the rs13428812 $\mathrm{A}>\mathrm{G}$ genotype in the non-GC group was 389AA, 276AG, and 43GG (HWE P=0.69). There was no significant difference in either the minor allele frequency or distribution of the rs13428812 genotype between the GC and non-GC groups.

Association between GC susceptibility and DNMT3A polymorphisms. Overall, patients homozygous for the rs6733868 $\mathrm{G}$ allele had a significantly decreased risk for gastric carcinogenesis as determined by logistic regression analysis after adjustment for age, gender, and HP infection status (OR, 0.621; 95\% CI, 0.402-0.958; P=0.031, Table II). When assessed by GC subtype, patients who were rs6733868 GG homozygotes had a significantly decreased risk for the development of intestinal cancers (OR, 0.494; 95\% CI, 0.274-0.890; P=0.019, Table II), whereas no significant association was found between this genotype and diffuse types of cancer. No significant association was found between GC susceptibility and rs13428812 (Table II).

Association between DNMT3A polymorphisms and GC susceptibility in subjects younger or older than 60 years. Patients who were rs6733868 GG homozygotes exhibited a significantly decreased risk for gastric carcinogenesis by logistic regression analysis after adjustment for age, gender, and HP infection status (OR, 0.534; 95\% CI, 0.319-0.922; $\mathrm{P}=0.024$, Table III). On the other hand, a significant association between rs13428812 and GC susceptibility was not seen in subjects classified based on age (whether younger or older than 60 years). 


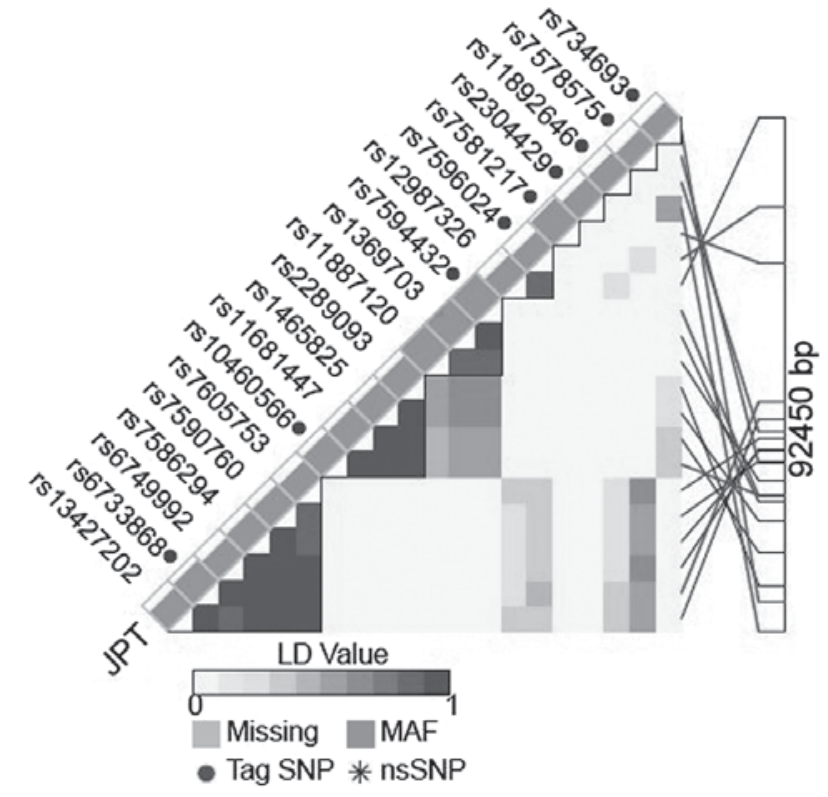

Figure 1. Linkage disequilibrium of DNMT3A. This figure was generated using snpinfo.niehs.nih.gov/snpinfo/snptag.html.
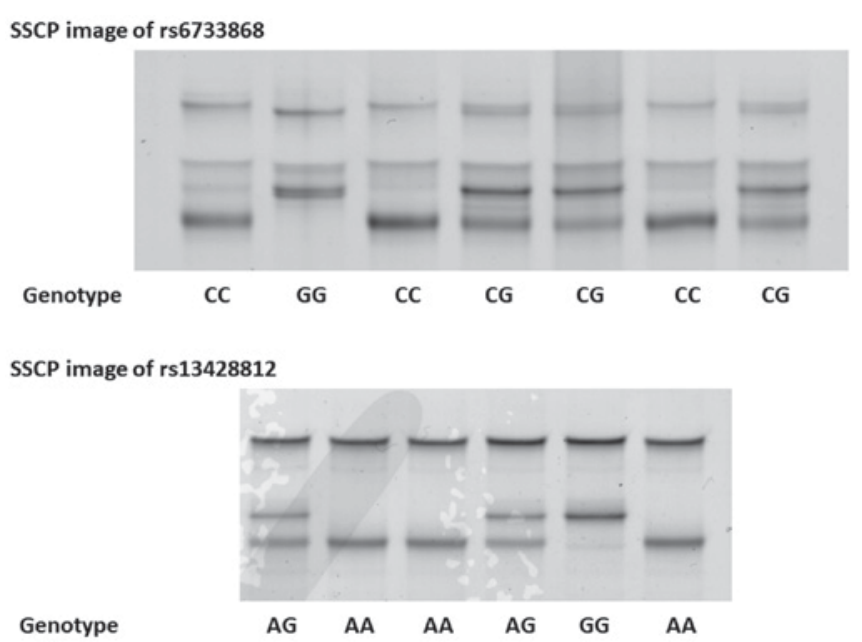

Figure 2. Products of polymerase chain reaction-SSCP analyses using clinical samples. Single-strand DNAs were separated by SSCP. These data enable determination of the genotype. SSCP, single-strand conformation polymorphism.

Characteristics of subjects and genotype frequencies in subjects in which gastric mucosal atrophy was assessed. For 409 of 708 controls, the degree of histologic gastritis could be assessed according to the updated Sydney system, and the characteristics and genotype distributions for these patients are shown in Table IV. In all 409 such subjects, the genotype distribution of rs6733868 was 165CC, 186CG, and 58GG (HWE $\mathrm{P}=0.67$ ), whereas that of rs 13428812 was $249 \mathrm{AA}, 136 \mathrm{AG}$, and 24GG (HWE $\mathrm{P}=0.39$ ). The mean age, male to female ratio, and HP positivity ratio were significantly higher in the SA group than the non-SA group (Table IV). The rs6733868G allele frequency in the SA and non-SA groups was 29.3 and $39.4 \%$, respectively $(\mathrm{P}=0.011)$. In addition, the proportion of patients who were rs6733868 GG homozygotes differed significantly between the SA and non-SA groups $(\mathrm{P}=0.0014)$. The
rs13428812G allele frequency was also significantly different between the SA and non-SA groups ( $\mathrm{P}=0.0082)$. In addition, the proportion of the AA homozygotes was significantly higher and that of the GG homozygotes significantly lower in the SA group than in the non-SA group $(\mathrm{P}=0.044$ and $\mathrm{P}=0.013$, respectively, Table IV).

Logistic regression analysis after adjustment for age, gender, and HP infection status indicated that the rs6733868 $\mathrm{CG}+\mathrm{GG}$ genotype was significantly associated with decreased severity of gastric mucosal atrophy (OR, 0.495; 95\% CI, 0.299-0.826; $\mathrm{P}=0.0069$, Table $\mathrm{V}$ ), whereas rs 13428812 was not associated with mucosal atrophy.

Association between HP infection status and DNMT3A polymorphisms in control subjects. The mean age and male to female ratio were significantly higher in HP-infected subjects than in uninfected subjects (Table VI). The minor allele frequency of both rs6733868 and rs13428812 was significantly higher in uninfected subjects than in HP-infected subjects. The proportions of patients who were rs6733868 GG and rs13428812 GG homozygotes were also significantly higher in HP-infected subjects than in uninfected subjects, whereas those of the rs6733868 CC and rs13428812 AA homozygotes were significantly lower in HP-infected than in uninfected subjects. The number of minor alleles of both rs6733868 and rs13428812 was significantly correlated with the frequency of HP infection $(\mathrm{P}=0.0070$ and $\mathrm{P}=0.0050$ by ANCOVA, respectively).

\section{Discussion}

Global DNA methylation patterns reportedly alter the hyper-methylation of $\mathrm{CpG}$ islands and the hypo-methylation of non-CpG islands (18). The action of de novo DNMTs, including DNMT3a, is responsible for this alteration during early tumorigenesis (19). In gastric carcinogenesis, overexpression of DNMT3a occurs in both cancerous and para-cancerous tissues (10). In addition, HP infection reportedly induces aberrant DNA methylation of $\mathrm{CpG}$ islands, subsequently suppressing the function of tumor suppressor genes in the gastric mucosa, and ultimately resulting in carcinogenesis $(20,21)$. HP infection reportedly does not directly induce either the mRNA or protein expression of DNMT1, DNMT3a, or DNMT3b in the gastric mucosa (22). However, the rs1550117 genetic polymorphism results in increased transcription of the DNMT3A gene, and an increase in the level of DNMT3A mRNA associated with gastric carcinogenesis (23). Thus, polymorphisms in DNMT3A are thought to play an important role in gastric carcinogenesis. However, although many studies have examined the relationship between rs1550117 and carcinogenesis, the potential association remains unclear. Based on the hypothesis that the other polymorphism in DNMT3A is more clearly associated with gastric carcinogenesis, we investigated the potential associations of other polymorphisms in DNMT3A that are not in strong linkage with rs1550117.

Specifically, we investigated two allele sites of DNMT3A (rs6733868 and rs13428812). The distributions of both rs6733868 and 13428812 in our control group were in $\operatorname{HWE}(\mathrm{P}=0.82$ and $\mathrm{P}=0.69$, respectively), and were similar to those reported in the Japanese population in the HapMap database $(\mathrm{P}=0.98$ and 
Table I. Subject characteristics and genotype frequencies.

\begin{tabular}{lcc}
\hline Characteristics & Non-GC group & GC group \\
\hline Number of subjects & 708 & 343 \\
Mean age \pm standard deviation (years) & $61.0 \pm 13.7$ & $65.3 \pm 11.4$ \\
Male:female & $405: 303$ & $239: 104$ \\
HP positive rate & $435 / 708$ & $296 / 343$ \\
rs6733868 C>G & & 130 \\
CC & 253 & 181 \\
CG & 338 & 32 \\
GG & 117 & $35.7 \%$ \\
G allele frequency & $40.4 \%$ & \\
rs13428812 A $>$ G & & 204 \\
AA & 389 & 128 \\
AG & 276 & 11 \\
GG & 43 & $21.9 \%$ \\
G allele frequency & $25.6 \%$ & $0.004^{\text {b }}$ \\
\hline
\end{tabular}

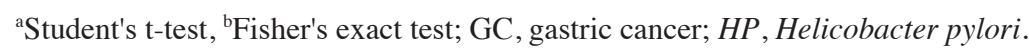

Table II. Association between DNMT3A polymorphisms and gastric cancer.

A, GG vs. $\mathrm{CC}+\mathrm{CG}$

\begin{tabular}{lrrrc}
\hline rs6733868 C>Ga, $(n)$ & CC & CG & GG & OR (95\% CI) \\
\hline Non-GC (708) & 253 & 338 & 117 & Reference \\
Overall GC (343) & 130 & 181 & 32 & $0.621(0.402-0.958)$ \\
Intestinal (195) & 84 & 103 & 15 & $0.494(0.274-0.890)$ \\
Diffuse (133) & 44 & 78 & 16 & $0.769(0.435-1.36)$ \\
(Unknown) & 2 & 0 & 1 & -0.031 \\
\hline
\end{tabular}

B, GG vs. AA+AG

\begin{tabular}{|c|c|c|c|c|c|}
\hline rs13428812 A> Ga , (n) & AA & $\mathrm{AG}$ & GG & OR $(95 \% \mathrm{CI})$ & P-value \\
\hline Non-GC (708) & 389 & 276 & 43 & Reference & - \\
\hline Overall GC (343) & 204 & 128 & 11 & $0.664(0.328-1.34)$ & 0.25 \\
\hline Intestinal (195) & 122 & 74 & 6 & $0.649(0.260-1.62)$ & 0.35 \\
\hline Diffuse (133) & 79 & 54 & 5 & $0.707(0.271-1.85)$ & 0.48 \\
\hline (Unknown) & 3 & 0 & 0 & - & - \\
\hline
\end{tabular}

${ }^{a}$ The number of subjects following regression analysis with adjustments for age, gender and $H P$ infection status. OR (95\% CI), odds ratio (95\% confidence interval); GC, gastric cancer; HP, Helicobacter pylori.

$\mathrm{P}=0.99$, respectively). We found a decreased association between DNMT3A homozygotes and gastric carcinogenesis, especially for intestinal types of cancer. However, no association was observed between rs13428812 and susceptibility to GC. HP infection is known to cause chronic inflammation, which subsequently progresses to atrophic gastritis, intestinal metaplasia, and finally, GC (15). In our present study, the rs6733868 minor allele was associated with a significantly lower risk of gastric mucosal atrophy. These observations suggest that in carriers of the rs6733868 minor allele, progression to gastric mucosal atrophy and subsequent development of GC may be inhibited in the homozygotes. In addition, a stronger association was detected in older rather than younger subjects, consistent with the expectation that intestinal types of GC occur as a result of an extended period of chronic inflammation and tissue rearrangement, including metaplastic change.

Previously, Cao et al (13) reported that rs1550117 is associated with higher risk of HP infection but not of gastric atrophy 
Table III. Association between DNMT3A polymorphisms and GC susceptibility in subjects younger or older than 60 years.

A, rs6733868

\begin{tabular}{|c|c|c|c|c|c|}
\hline Age & $\mathrm{CC}$ & $\mathrm{CG}$ & GG & GG vs. $\mathrm{CC}+\mathrm{CG}, \mathrm{OR}(95 \% \mathrm{CI})$ & P-value \\
\hline \multicolumn{6}{|l|}{$<60$ years } \\
\hline Non-GC (278) ${ }^{\mathrm{a}}$ & 95 & 135 & 48 & Reference & - \\
\hline $\mathrm{GC}(105)^{\mathrm{a}}$ & 40 & 54 & 11 & $0.756(0.360-1.59)$ & 0.46 \\
\hline \multicolumn{6}{|l|}{$\geq 60$ years } \\
\hline Non-GC (429) ${ }^{\mathrm{a}}$ & 158 & 202 & 69 & Reference & - \\
\hline $\mathrm{GC}(238)^{\mathrm{a}}$ & 90 & 127 & 21 & $0.534(0.319-0.922)$ & 0.024 \\
\hline
\end{tabular}

B, rs 13428812

\begin{tabular}{lrrrr}
\hline Age & AA & AG & GG & GG vs. AA+AG, OR (95\% CI) \\
\hline$<60$ years & & & & P-value \\
Non-GC $(278)^{\mathrm{a}}$ & 146 & 114 & 18 & Reference \\
GC $(105)^{\mathrm{a}}$ & 62 & 41 & 2 & $0.344(0.075-1.58)$ \\
$\geq 60$ years & 243 & 161 & 25 & Reference \\
Non-GC $(429)^{\mathrm{a}}$ & 142 & 87 & 9 & 0.17 \\
GC $(238)^{\mathrm{a}}$ & $147(0.329-1.65)$ & 0.46 \\
\hline
\end{tabular}

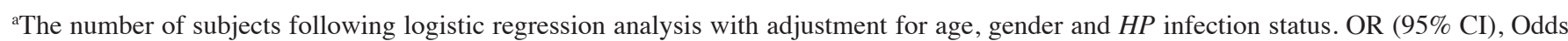
ratio (95\% confidence interval); GC, gastric cancer; HP, Helicobacter pylori.

Table IV. Characteristics and genotype frequencies of subjects in whom histological findings were evaluated.

\begin{tabular}{|c|c|c|c|c|}
\hline Characteristics & Total & Non-SA group & SA group & P-value \\
\hline Number of subjects & 409 & 310 & 99 & \\
\hline Mean age \pm SD (years) & $59.9 \pm 13.3$ & $58.4 \pm 13.7$ & $64.4 \pm 11.1$ & $0.0001^{\mathrm{a}}$ \\
\hline Male:female & 240:169 & $168: 142$ & $72: 27$ & $0.0010^{\mathrm{b}}$ \\
\hline H. pylori positive rate & $262 / 409$ & $169 / 310$ & 93/99 & $<0.0001^{\mathrm{b}}$ \\
\hline \multicolumn{5}{|l|}{ rs6733868 C>G } \\
\hline $\mathrm{CC}$ & 165 & 111 & 54 & \multirow[t]{3}{*}{$0.0014^{\mathrm{b}}$} \\
\hline $\mathrm{CG}$ & 186 & 154 & 32 & \\
\hline GG & 58 & 45 & 13 & \\
\hline $\mathrm{G}$ allele frequency $(\%)$ & 36.9 & 39.4 & 29.3 & $0.011^{\mathrm{b}}$ \\
\hline \multicolumn{5}{|l|}{$\mathrm{rs} 13428812 \mathrm{~A}>\mathrm{G}$} \\
\hline AA & 249 & 180 & 69 & \multirow[t]{2}{*}{$0.044^{\mathrm{b}}$} \\
\hline $\mathrm{AG}$ & 136 & 107 & 29 & \\
\hline GG & 24 & 23 & 1 & $0.013^{\mathrm{b}}$ \\
\hline $\mathrm{G}$ allele frequency $(\%)$ & 22.5 & 28.4 & 15.7 & $0.0082^{\mathrm{b}}$ \\
\hline
\end{tabular}

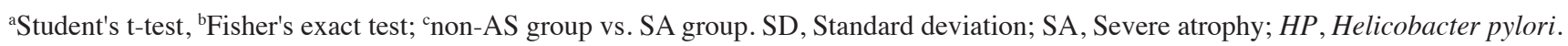

or GC. Those authors speculated that this DNMT3A polymorphism facilitates HP infection by promoting methylation of the gene encoding MUC-1, a membrane-bound mucin expressed on the surface of gastric epithelial cells that normally provides a protective barrier against HP infection (24). Interestingly, our results showed that both rs6733868 and rs13428812 were strongly associated with the risk of HP infection. Specifically, rs6733868 was associated with higher HP infection risk, severe gastric mucosal atrophy, and susceptibility to GC, especially intestinal types of cancer, whereas rs13428812 was associated only with HP infection risk. Potential associations of rs6733868 with clinical disorders have not been reported. In addition, there are no data available regarding the influence of either polymorphism on the expression or function of DNMT3a. However, we 
Table V. Association between DNMT3A polymorphisms and gastric mucosal atrophy.

A, rs6733868 C> $\mathrm{G}^{\mathrm{a}}$

\begin{tabular}{lrrrc}
\hline Atrophy status, (n) & CC & CG & GG & OR (95\% CI), CG+GG vs. CC \\
\hline Non-SA (310) & 111 & 154 & 45 & Reference \\
SA (99) & 54 & 32 & 13 & $0.495(0.299-0.826)$ \\
\hline
\end{tabular}

$\mathrm{B}, \mathrm{rs} 13428812 \mathrm{~A}>\mathrm{G}^{\mathrm{a}}$

\begin{tabular}{lrrrc}
\hline Atrophy status, (n) & AA & AG & GG & OR (95\% CI), AG+GG vs. AA \\
\hline Non-SA (310) & 180 & 107 & 23 & Reference \\
SA (99) & 69 & 29 & 1 & $0.909(0.518-1.58)$ \\
\hline
\end{tabular}

${ }^{a}$ The number of subjects following logistic regression analysis with adjustment for age, gender and $H P$ infection status. OR (95\% CI), Odds ratio (95\% confidence interval); SA, severe atrophy; $H P$, Helicobacter pylori.

Table VI. Association between HP infection status and DNMT3A polymorphisms in control subjects.

\begin{tabular}{|c|c|c|c|}
\hline Variable & HP uninfected & HP infected & P-value \\
\hline No. of subjects & 273 & 435 & \\
\hline Mean age \pm SD (years) & $59.9 \pm 15.3$ & $61.7 \pm 12.5$ & $0.084^{\mathrm{a}}$ \\
\hline Male:female & $133: 140$ & $272: 163$ & $0.0003^{\mathrm{b}}$ \\
\hline \multicolumn{4}{|l|}{ rs6733868 C>G } \\
\hline $\mathrm{CC}$ & 88 & 165 & \multirow[t]{2}{*}{$0.018^{\mathrm{b}}$} \\
\hline $\mathrm{CG}$ & 125 & 213 & \\
\hline GG & 60 & 57 & $0.0025^{\mathrm{b}}$ \\
\hline $\mathrm{G}$ allele frequency $(\%)$ & 44.9 & 33.0 & $0.0075^{\mathrm{b}}$ \\
\hline \multicolumn{4}{|l|}{$\mathrm{rs} 13428812 \mathrm{~A}>\mathrm{G}$} \\
\hline AA & 135 & 254 & \multirow[t]{2}{*}{$0.024^{\mathrm{b}}$} \\
\hline $\mathrm{AG}$ & 114 & 162 & \\
\hline GG & 24 & 19 & $0.023^{\mathrm{b}}$ \\
\hline $\mathrm{G}$ allele frequency $(\%)$ & 30.0 & 23.0 & $0.0059^{\mathrm{b}}$ \\
\hline
\end{tabular}

${ }^{\mathrm{a} S t u d e n t ' s ~ t-t e s t, ~}{ }^{\mathrm{b}}$ Fisher's exact test; SD, standard deviation; HP, Helicobacter pylori.

hypothesize that these polymorphisms affect the expression of DNMT3a to varying degrees, as many studies suggest. If so, the difference in risk association between rs6733868 and rs13428812 may depend on the difference in the number of affected genes and/or the degree of methylation. Of course, the expression of DNMT3a is not regulated only by DNMT3A polymorphisms. Kim et al (25) reported that DNMT3A mutations and allelic losses, which decrease the enzymatic activity of the protein product, are observed in many solid cancers, suggesting that abnormal expression or accumulation of DNMT3a in cancer tissues may be due to defects in the degradation of mutant products rather than to the polymorphisms themselves.

There are some clinical limitations to our study. The first limitation is that our subjects were patients who visited our hospital for either endoscopic examinations due to specific symptoms or further follow-up after health examinations.
Subjects reporting no symptoms are essential for control groups. In addition, we could not confirm whether very small histologic neoplasia was present in any of the control group subjects. A second limitation is that we assessed histologic gastritis using biopsy samples only from the antrum, because the antral mucosa is affected by HP infection for the longest period. Clearer results might have been obtained if the degree of gastritis in the corpus was assessed at the same time. A third limitation is that ethnicity is an important factor affecting heterogeneity. Although different countries and populations have different dietary and lifestyle habits (26), this retrospective research was performed at a single Japanese center.

In conclusion, regarding the influence of rs6733868, our results suggest that the risk of HP infection decreases depending on the number of minor alleles, the risk of severe gastric mucosal atrophy decreases in minor allele carriers, 
and the risk of developing GC decreases in minor allele homozygotes. In contrast, rs13428812 is associated only with HP infection and not with severe gastric mucosal atrophy or gastric carcinogenesis. Thus, the data suggest that both DNMT3A polymorphisms participate in the progression from HP to gastric mucosal atrophy and ultimately to gastric carcinogenesis in both degree and manner.

\section{Acknowledgements}

Not applicable.

\section{Funding}

No funding was received.

\section{Availability of data and materials}

All data generated or analyzed during this study are included in this published article.

\section{Authors' contributions}

WJ analyzed the data and wrote the paper. TO, MN, NS, HT, $\mathrm{TH}, \mathrm{MO}, \mathrm{TN}$ and $\mathrm{RH}$ obtained the samples and performed the experiments to obtain the data. TaS determined the genotype. TT and ToS obtained the samples and participated in the design of the study. TA was responsible for the conception and design of the study. All authors have read and approved the final manuscript.

\section{Ethics approval and consent to participate}

The Ethics Committees of Fujita Health University and Kanazawa Medical University approved the protocol, and written informed consent was obtained from all participating subjects.

\section{Patient consent for publication}

All patients gave informed consent.

\section{Competing interests}

The authors declare that they have no competing interests.

\section{References}

1. Neugut AI, Hayek $\mathrm{H}$ and Howe G: Epidemiology of gastric cancer. Semin Oncol 23: 281-291, 1996.

2. Yasui W, Sentani K, Motoshita J and Nakayama H: Molecular pathobiology of gastric cancer. Scand J Surg 95: 225-231, 2006.

3. Watanabe Y, Kurata JH, Mizuno S, Mukai M, Inokuchi H, Miki K, Ozasa K and Kawai K: Helicobacter pylori infection and gastric cancer. A nested case-control study in a rural area of Japan. Dig Dis Sci 42: 1383-1387, 1997.

4. Ozasa K, Kurata JH, Higashi A, Hayashi K, Inokuchi H, Miki K, Tada M, Kawai K and Watanabe Y: Helicobacter pylori infection and atrophic gastritis: A nested case-control study in a rural town in Japan. Dig Dis Sci 44: 253-256, 1999.

5. Correa P: A human model of gastric carcinogenesis. Cancer Res 48: 3554-3560, 1988.
6. Uemura N, Okamoto S, Yamamoto S, Matsumura N, Yamaguchi S, Yamakido M, Taniyama K, Sasaki N and Schlemper RJ: Helicobacter pylori infection and the development of gastric cancer. N Engl J Med 345: 784-789, 2001.

7. Hamajima N, Naito M, Kondo T and Goto Y: Genetic factors involved in the development of Helicobacter pylori-related gastric cancer. Cancer Sci 97: 1129-1138, 2006.

8. Sapari NS, Loh M, Vaithilingam A and Soong R: Clinical potential of DNA methylation in gastric cancer: A meta-analysis. PLoS One 7: e36275, 2012.

9. Li E: Chromatin modification and epigenetic reprogramming in mammalian development. Nat Rev Genet 3: 662-673, 2002.

10. Ding WJ, Fang JY, Chen XY and Peng YS: The expression and clinical significance of DNA methyltransferase proteins in human gastric cancer. Dig Dis Sci 53: 2083-2089, 2008.

11. Zhang W, Xu Y, Ma G, Qi W, Gu H and Jiang P: Genetic polymorphism of DNA methyltransferase 3A rs1550117 A>G and risk of cancer: A meta-analysis. J Invest Surg 28: 346-353, 2015.

12. Li H, Li W, Liu S, Zong S, Wang W, Ren J, Li Q, Hou F and Shi Q: DNMT1, DNMT3A and DNMT3B polymorphisms associated with gastric cancer risk: A systematic review and meta-analysis. EBioMedicine 13: 125-131, 2016.

13. Cao XY, Jia ZF, Cao DH, Kong F, Jin MS, Suo J and Jiang J: DNMT3a rs1550117 polymorphism association with increased risk of Helicobacter pylori infection. Asian Pac J Cancer Prev 14: 5713-5718, 2013.

14. Yang XX, He XQ, Li FX, Wu YS, Gao Y and Li M: Risk-association of DNA methyltransferases polymorphisms with gastric cancer in the Southern Chinese population. Int J Mol Sci 13: 8364-8378, 2012.

15. Correa P: Human gastric carcinogenesis: A multistep and multifactorial process-First American cancer society award lecture on cancer epidemiology and prevention. Cancer Res 52: 6735-6740, 1992.

16. Arisawa T, Nakamura M, Otsuka T, Jing W, Sakurai N, Takano H, Hayashi T, Ota M, Nomura T, Hayashi R, et al: Genetic polymorphisms of MAFK, encoding a small Maf protein, are associated with susceptibility to ulcerative colitis in Japan. World J Gastroenterol 23: 5364-5370, 2017

17. Ota M, Tahara T, Otsuka T, Jing W, Nomura T, Hayashi R, Shimasaki T, Nakamura M, Shibata T and Arisawa T: Association between receptor interacting serine/threonine kinase 2 polymorphisms and gastric cancer susceptibility. Oncol Lett 15: 3772-3778, 2018

18. Li W and Chen BF: Aberrant DNA methylation in human cancers. J Huazhong Univ Sci Technolog Med Sci 33: 798-804, 2013.

19. Fernandez AF, Assenov Y, Martin-Subero JI, Balint B, Siebert R, Taniguchi $\mathrm{H}$, Yamamoto $\mathrm{H}$, Hidalgo M, Tan AC, Galm O, et al: A DNA methylation fingerprint of 1628 human samples. Genome Res 22: 407-419, 2012.

20. Maekita T, Nakazawa K, Mihara M, Nakajima T, Yanaoka K, Iguchi M, Arii K, Kaneda A, Tsukamoto T, Tatematsu M, et al: High levels of aberrant DNA methylation in Helicobacter pylori-infected gastric mucosae and its possible association with gastric cancer risk. Clin Cancer Res 12: 989-995, 2006.

21. Tahara T, Arisawa T, Shibata T, Wang FY, Nakamura M, Sakata M, Nagasaka M, Takagi T, Kamiya Y, Fujita H, et al: Risk prediction of gastric cancer by analysis of aberrant DNA methylation in non-neoplastic gastric epithelium. Digestion 75: 54-61, 2007.

22. Nakajima T, Maekita T, Oda I, Gotoda T, Yamamoto S, Umemura S, Ichinose M, Sugimura T, Ushijima T and Saito D: Higher methylation levels in gastric mucosae significantly correlate with higher risk of gastric cancers. Cancer Epidemiol Biomarkers Prev 15: 2317-2321, 2006.

23. Fan H, Liu D, Qiu X, Qiao F, Wu Q, Su X, Zhang F, Song Y, Zhao Z and Xie W: A functional polymorphism in the DNA methyltransferase-3A promoter modifies the susceptibility in gastric cancer but not in esophageal carcinoma. BMC Med 8: 12, 2010.

24. Yamada N, Nishida Y, Tsutsumida H, Hamada T, Goto M, Higashi M, Nomoto $\mathrm{M}$ and Yonezawa S: MUC1 expression is regulated by DNA methylation and histone $\mathrm{H} 3$ lysine 9 modification in cancer cells. Cancer Res 68: 2708-2716, 2008.

25. Kim MS, Kim YR, Yoo NJ and Lee SH: Mutational analysis of DNMT3A gene in acute leukemias and common solid cancers. APMIS 121: 85-94, 2013.

26. Menotti A and Puddu PE: How the seven Countries study contributed to the definition and development of the Mediterranean diet concept A 50-year journey. Nutr Metab Cardiovasc Dis 25: 245-252, 2015. 